\title{
A INFÂNCIA EM BACHELARD E STEINER: UM PONTO DE VISTA DA EDUCAÇÃO ANTROPOSÓFICA CONTRA A CRÍTICA DE ONFRAY
}

\section{CHILDHOOD IN BACHELARD AND STEINER: A VIEW OF ANTHROPOSOPHIC EDUCATION AGAINST ONFRAY CRITICISM}

\author{
Gabriel Kafure da Rocha ${ }^{*}$, Debora Maria dos Santos², Ronald Oliveira Pinho ${ }^{3}$ \\ ${ }^{1}$ Doutorando em Filosofia pela UFRN, Professor de Filosofia do IF Sertão - PE, Petrolina, PE, Brasil, gkafure@gmail.com \\ ${ }^{2}$ Mestre em Consumo pela UFRPE, Recife, PE, Brasil, deboramariasantos1@gmail.com \\ ${ }^{3}$ Graduado em Ciências Humanas pela UNILAB, Fortaleza, CE, Brasil, ronaldoliveiradepinho@outlook.com \\ ${ }^{*}$ Autor de correspondência
}

\begin{abstract}
Resumo
O presente estudo crítico pretende tratar do ato de filosofar enquanto possibilidade de retomada da infância mais longínqua e que permanece por toda a vida. O ato criador é antes de tudo um potencial cósmico, pelo qual a criança se apropria de seus mundos interiores em toda a sua inteireza na multiplicidade das infâncias, de modo que a infância pode e deve habitar em cada um de nós. Nesse sentido faremos um estudo crítico aproximando a filosofia de Gaston Bachelard (1884-1962) com Rudolf Steiner (1861-1925). Um lampejo dessa aproximação já foi realizado anteriormente por Michel Onfray (1959 -) em seu livro Cosmos, contudo, por meio de um ponto de vista crítico diferente de Onfray (que considera o trabalho de Steiner duvidoso), gostaríamos de encontrar aproximações possíveis entre o humanismo bachelardiano e a antroposofia, tentando conciliar principalmente os aspectos de transição entre a infância e a juventude, que ambos empreender e que são baseados na relação do ser com o cosmos, a natureza e seus elementos. Para isso, partiremos do texto A poética do devaneio de Bachelard fazendo uma intersecção com a conferência $O$ valor moral da cultura científica, bem como, nos utilizaremos de dois textos de Steiner, A filosofia da liberdade e A educação da criança segundo a ciência espiritual. Nesse processo investigativo, utilizamos uma metodologia praxeológica que vai desde uma investigação contextual sobre os aspectos filosóficos, pedagógicos e antropológicos que nos levaram aos resultados do imaginário da infância bem como suas implicações morais na construção subjetiva do conhecimento.
\end{abstract}

Palavras-Chave: Imaginação; Infância; Moral.

\begin{abstract}
The present critical study intends to deal with the act of philosophizing as a possibility of retaking the most distant childhood that remains for a lifetime. The creative act is first and foremost a cosmic potential, whereby the child appropriates his inner worlds in all their entirety in the multiplicity of childhoods, so that childhood can and must dwell in each of us. In this sense we will make a critical study approaching the philosophy of Gaston Bachelard (1884-1962) with Rudolf Steiner (1861-1925). A glimpse of this approach has already been made earlier by Michel Onfray (1959 -) in his book Cosmos, however, from a critical point of view different from Onfray (who considers Steiner's work doubtful), we would like to find possible approximations between the Bachelardian humanism and anthroposophy, trying mainly to reconcile the aspects of transition between childhood and youth, which both undertake and which are based on the relationship of being with the cosmos, nature and its elements. For this, we will start from the text The poetic of Bachelard daydream making an intersection with the conference The moral value of scientific culture, as well as we will use two texts by Steiner, The Philosophy of Freedom and The Education of the Child according to Spiritual Science. In this investigative process, we use a praxeological methodology that goes from a contextual investigation on the
\end{abstract}


philosophical, pedagogical and anthropological aspects that led us to the results of the childhood imaginary as well as their moral implications in the subjective construction of knowledge.

Keywords: Imagination; Childhood;Moral

(C)UNIS-MG. All rights reserved.

How to cite this article:

ROCHA, Gabriel Kafure da; SANTOS, Debora Maria dos. PINHO, Ronald Oliveira. A INFÂNCIA EM BACHELARD E STEINER: UM PONTO DE VISTA DA EDUCAÇÃO ANTROPOSÓFICA CONTRA A CRÍTICA DE ONFRAY. Interação, Varginha, MG, v. 21, p. 51 - 67, 2019. ISSN 1517-848X / ISSN 2446-9874.

Disponível em: https://periodicos.unis.edu.br/index.php/interacao/article/view/284

DOI: https://doi.org/10.33836/interacao.v21i1.284

\title{
INTRODUÇÃO
}

\begin{abstract}
Quando nossas sociedades encontraram uma maneira de manter o homem no nível moral da adolescência, elas resolveram em grande parte a questão moral e a questão social. Mas seria errado se alguém buscasse a razão desse alto valor moral do ambiente escolar apenas na organização sábia de uma disciplina. Nós devemos julgar no nível das almas, no nível dos espíritos. As classes sólidas e ordenadas são as classes em que o conhecimento se apresenta em sua novidade, no frescor da descoberta. Então sentimos que as mentes se retificam, se constituem, se universalizam. O tédio de viver uma consciência vaga de uma psiquê dividida dá lugar à alegria de pensar. (BACHELARD, 1993, p. 7)
\end{abstract}

A infância emana de tantas fontes que seria tão inútil traça-la numa geografia quanto escrever-Ihe a história e sua filosofia. Assim, nesse aspecto poético-histórico, como Aristóteles já emanava da necessidade de uma história do que deveria ser e não do que é, o historiador francês Philippe Ariès (1981) defende em seus estudos que a concepção de infância como uma fase da vida que necessita de atenção especial. Ora, a infância foi uma invenção trazida pela modernidade, a partir do século XVI, onde passou a ser pensada como uma fase da vida, que vem a ser superada pela racionalidade da idade adulta. Ou seja, a infância foi inventada como uma ruptura, em que a criança não é mais um mini-adulto, mas sim uma fase em que

O sentimento da infância não significa o mesmo que afeição pelas crianças: corresponde à consciência da particularidade infantil, essa particularidade que distingue essencialmente a criança do adulto, mesmo jovem. Essa consciência não existia (ARIÈs, 1981, p. 99).

Manuel Sarmento (2003) destaca que a criança se insere na sociedade como um ator social portador de novidades e que faz renascer o mundo, trazendo consigo a leveza e a renovação de que tudo é possível. Por esse motivo, o autor afirma que a infância é um "entre-lugar", pois está entre o que é consignado pelos adultos e o que é reinventado pelas crianças, sendo um lugar socialmente construído e renovado pela ação das crianças. 
ROCHA, Gabriel Kafure da; SANTOS, Debora Maria dos. PINHO, Ronald Oliveira.

A partir da perspectiva de Bachelard, é possível perceber que habita em nós uma infância em potencial e que reencontramos ela em nossos devaneios, revivendo possibilidades, talvez buscando ser ou continuar sendo um "portador de novidades" que acredita que tudo ainda é possível, idealizando os mundos que foram construídos enquanto criança. Segundo autor:

\begin{abstract}
E é assim que há comunicação entre um poeta da infância e seu leitor, por intermédio da infância que dura em nós. Essa infância, aliás, permanece como uma simpatia de abertura para a vida, permite-nos compreender e amar as crianças como se fossemos os seus iguais numa vida primeira (BACHELARD, 2009, p. 95).
\end{abstract}

Historicamente, a infância é feita de representações daquilo que se percebe, registra e produz sobre ela, através de discursos produzidos por adultos que segundo Buckingham (2007, p. 34) "muitas vezes dizem mais sobre os investimentos adultos e infantis na ideia da infância do que sobre a realidade das vidas das crianças", sendo "frequentemente imbuídas da nostalgia de uma Era de Ouro perdida de brincadeira e liberdade" (BACHELARD, 2009, p.24). Bachelard, mostra esse sentimento em seu texto quando fala dos devaneios ligados à infância, representados em poemas saudosos, ligados a infância e a felicidade simples, recorre a imagem da infância situada em um lugar de pureza e arquétipo da felicidade simples.

Segundo Steiner, a primeira infância é o um período de encantamento, não deve ser pragmatizada na relação com as letras e números, mesmo que, o próprio Steiner diga que sua felicidade na infância foi ter se encontrado com a geometria. É na primeira fase da infância que elas desenvolvem bons hábitos, como aprender a brincar, respeitar os outros e a natureza.

Essa estética teria colocado o corpo em seu centro, teria chamado a nostalgia e a infância para o resgate, teria confiado na subjetividade e em sua capacidade de liberar a meditação, teria significado, percepções, Imaginação, as afeições para dar-lhes uma autoridade arquitetônica, ela teria suposto em panteísmo singular - que Bachelard chamado pancalismo (ONFRAY, 1998, p. 19).

Segundo Bachelard, quando meditamos sobre a criança que fomos, e na maneira como a criança não se dissocia do mundo "atingimos uma infância anônima, puro foco de vida, vida primeira, vida humana primeira." (BACHELARD, 2009, p. 120). E essa lembrança nos faz reviver o arquétipo da infância, como um pancalismo onde tudo é beleza e o belo está em tudo.

Nesse sentido, em sua isotópica das imagens ${ }^{1}$, Durand, discípulo de Bachelard, sugere que “Bachelard verifica que a infância é precisamente a última base da anamnese” (DURAND, 1993, p.

\footnotetext{
${ }^{1}$ Classificada sob três sistemas reflexológicos, a isotopia das imagens converge para uma ideia onde o imaginário se coloca como um museu de todas as imagens, mitos e percepções do mundo que constroem a cultura.
} 
ROCHA, Gabriel Kafure da; SANTOS, Debora Maria dos. PINHO, Ronald Oliveira.

68), de modo que a infância impede a dissolução do anterior no vindouro. Ou seja, ela é uma condição da existência da anamnese ${ }^{2}$ dos simbolismos contidos nas fantasias.

\section{STEINER E BACHELARD}

Rudolf Steiner e Gaston Bachelard são pensadores e filósofos que não tiveram contato algum, mas que de certo modo, beberam em influências comuns do romantismo e idealismo e guardam uma possível aproximação a partir de temas esotéricos tais como alquimia e ocultismo. Nesse sentido, ambos têm uma visão do cosmos que vale à pena ser ressaltada e quiçá comparada.

Steiner como um dissidente da teosofia de Blavatsky, cria a antroposofia no intuito de estudar uma maneira de observar a relação entre o homem e o cosmos onde a realidade é descrita em vários planos que mesmo permeados por uma espiritualidade, tem como foco principal o desenvolvimento do ser humano. É possível entender que, de acordo com Steiner, os níveis de consciência apresentados estão diretamente ligados aos aspectos simbólicos e imaginários antropocósmicos.

É justamente nesse aspecto que o mundo, para Steiner, é o horizonte de nossas vivências enquanto sensações, percepções, conceitos e ideais, assim também como nossas ilusões. A ciência que norteia sua investigação é a noologia ${ }^{3}$, ou seja, a ciência espiritual.

Toda essa constatação pode ser feita através da cosmovisão antroposófica, pela qual a realidade material deixa de ser a única possível para ser parte integrante de realidades mais amplas, numa visão que passa então a ser sistêmica, holística, conforme afirmação de Veiga (1996), abarcando o físico e o suprafisico ou, como dizia Steiner (passim), o sensível e o suprassensível. (ROMANELLI, 2015, p. 57).

Tal constatação dessa relação entre o sensível e o suprassensível, que tem raiz filosófica desde Platão, cria entre Bachelard e Steiner uma aproximação do ponto de vista em que a poética (sensível) e o suprassensível (razão/ciência) tem sua raiz na maneira de apreensão do conhecimento dual, oposto, mas também complementar. Steiner ainda afirma que,

A Teoria do Conhecimento deve ser uma investigação científica daquilo que todas as outras ciências pressupõem sem examiná-lo: o próprio conhecer. [...] o sucesso de muitas pesquisas científicas depende essencialmente da capacidade de se colocarem problemas corretamente. [...] a Teoria do Conhecimento [...] só chegará a bom termo se as perguntas básicas forem adequadamente formuladas. (STEINER, 1985, p. 14-15).

\footnotetext{
${ }^{2}$ Rememoração espiritual, da memória celular trazida de outras vidas.

${ }^{3}$ Noologia enquanto ciência espiritual seria a investigação que proporciona a visão integrada da relação entre indivíduo e cosmos.
} 
Também aí Bachelard concordaria de que não existem problemas insolúveis, mais sim mal formulados, e aí nós teríamos que chegar ao ponto justamente de qual a problemática que pretendemos abordar na formação moral antroposófica e como ela pode se aproximar da filosofia de Bachelard? Gostaríamos de citar a crítica de Onfray, ao mesmo tempo assumindo que tal concepção reduz a concepção de Steiner ao princípio pré-científico de Bachelard, o que é reducionista. Ainda que no aspecto literário ambos possam ser pré-científicos, isso não significa que sejam pré-científicos na mesma medida.

\begin{abstract}
Bachelard submete, pedagogicamente, a duvidar, a uma revisão contínua, tornando a progressão escolar um modelo para o professor quanto à informação. Ao centralizar a educação na razão em uma relação pedagógico-docente, específica da escola, Bachelard nunca se esquece de instruir o professor a sair de sua solidão magistral para mais uma vez entrar em uma dinâmica viva de vida, aprendizado contínuo de si mesmo e dos outros (WUNENBURGER, 2014, p. 195).
\end{abstract}

De forma introdutória é possível entender que a diferença está no método que ambos utilizam, ao passo que Bachelard aplicou efetivamente sua prática como professor no ensino secundário em Bar-sur-Aube (há relatos também de que entre 1929-1925 Bachelard idealizou uma escola pública na cidade, o que efetivamente ocorrer e veio a se chamar 'Gaston Bachelard) e depois no ensino universitário em Dijon e depois na Sorbornne em Paris. Steiner experienciou a direção de uma escola a partir de sua teoria antroposófica, o nome da escola, Waldorf, se deu pelo fato de que Emil Molt, um diretor de uma fábrica de cigarros chamada Waldorf/Astória na cidade de Stuttgart, ao se identificar e se comprometer com as causas trabalhistas, sugeriu ao Steiner para fazer palestras aos trabalhadores sobre sua metodologia de educação. Em princípios de 1919, os próprios trabalhadores tiveram interesse de que seus filhos pudessem receber uma educação mais adequada e tal iniciativa prevaleceu até hoje em dia, onde na última década a pedagogia Waldorf cresceu muito no Brasil, ainda que para camadas e classes sociais mais abastadas.

Nesse sentido crítico, entendemos por meio de Onfray, é que começamos agora a traçar críticas teóricas a esse tipo de linha de pensamento antroposófica, que acaba não operando nos níveis racionais mais elevados, acabando por ser um obstáculo teórico em si.

\footnotetext{
Pensando não racionalmente, mas instintivamente, Steiner recorre a comparações que, segundo ele, são razoáveis. Bachelard teria estigmatizado a quantidade de ocultista ativado em seus obstáculos epistemológicos de desenvolvimento intelectual. Assim, alguns dos obstáculos que se distinguem pela formação filósofo do espírito científico (substancialista, verbal, animista) são psicanálise lúcida óbvia do conhecimento objetivo proposto pelo pensador do leitor elementos. (ONFRAY, 2016, p. 167).
}

Em que medida há essa diferença entre um proposta objetiva da crítica literária de Bachelard e da educação antroposófica de Steiner? Precisamos então primeiramente entender a 
ROCHA, Gabriel Kafure da; SANTOS, Debora Maria dos. PINHO, Ronald Oliveira.

relação entre educação e cosmos em Steiner. Este, pode ser interpretada de uma de uma maneira que se aproxima de um panteísmo ${ }^{4}$ em que o ser humano se identifica com a natureza, ele afirma que

A existência toda é como uma planta, não abrangendo apenas o que se apresenta à vista, mas contendo em seu âmago um estado futuro. Quem vê uma planta apresentando apenas folhas sabe perfeitamente que ela terá, dentro de algum tempo, flores e frutos; contudo, a planta já possui, de maneira invisível, a disposição para essas flores e frutos. (STEINER, 1996, p. 2).

Apesar de Onfray fazer essa crítica ao Steiner, em vários momentos da obra poética de Bachelard, há essa mesma metáfora da árvore sob o ponto de vista da imaginação formal como uma das réplicas da relação do homem com a natureza. Ou seja, Onfray se vale de um Bachelard epistemológico para enfatizar sua crítica, porém não vê que na totalidade do pensamento do pensamento de Bachelard há uma grande semelhança com o método, ainda que pré-científico, do que Steiner faz.

Note-se em contraposição a Onfray, a partir do próprio ponto de vista de Bachelard, a semelhança de raciocínio é latente:

Viver como uma árvore! Que crescimento! Que profundidade! Que retidão! Que verdade!
No mesmo instante, dentro de nós, sentimos as raízes trabalharem, sentimos que o
passado não está morto, que temos algo a fazer, hoje, em nossa vida obscura, em nossa
vida subterrânea, em nossa vida solitária, em nossa vida aérea. A árvore está em toda a
parte ao mesmo tempo. A velha raiz - na imaginação não existem raízes jovens - vai
produzir uma flor nova. A imaginação é uma árvore. Tem as virtudes integrantes da
árvore. É raiz e ramagem. Vive entre a terra e o céu. Vive na terra e no vento. A árvore
imaginada é insensivelmente a árvore cosmológica, a árvore que resume um universo, que
faz um universo. (BACHELARD, 2001, p. 230).

É claro que não podemos ignorar que Onfray estaria se referindo ao fato de que Bachelard coloca os assuntos nos seus devidos lugares, especificando que está fazendo crítica literária ao examinar poeticamente o caráter imagético da árvore e não o aspecto comparativo/analógico como metáfora ao ser humano, o que seria um obstáculo epistemológico. Contudo, no que diz respeito à Steiner, nota-se que Onfray não percebe o devido valor da prática antroposófica enquanto educação e medicina alternativa homeopática. Ao mesmo tempo, ele continua sua

\footnotetext{
4 "Steiner rejeita as abordagens teórica, conceitual, estatística e universitária, e convida a observação sobre o terreno específico dos campos, as florestas, o gado em seus locais de pastagem. Não há necessidade de perguntar aos livros a verdade do mundo da natureza, do universo geológico, vegetal e animal; devemos questionar diretamente o real e dizer por que e como a beterraba, por exemplo, mantém um relacionamento íntimo com o ambiente cósmico da Terra." (ONFRAY, 2016, p. 166).
} 
crítica na relação entre a antroposofia e a agricultura biodinâmica, como uma espécie de saudosismo que ignoraria as inovações tecnológicas e técnicas agronômicas ${ }^{5}$.

A performativa de Steiner é colocada em uma lógica como, por exemplo, acha que a relação esquema de terra, planta, solo, subsolo como a relação homem, cabeça, diafragma, entranhas. O que funciona no registro da agricultura é deduzido por uma comparação com o registro humano. Como a cabeça do ser humano, a planta recebe as influências dos efeitos do céu mais próximo, ou seja, o Sol, Mercúrio, Vênus e a Lua; como entranhas humanas, o subsolo geológico é sujeita à lei dos efeitos do céu distante, incluindo os de Júpiter, Saturno e Marte. O solo aparece como um órgão do organismo: é um diafragma, a barriga do domínio agrícola. Steiner, assim, confere uma vida mágica a tudo o que é, uma vida em relação às forças invisíveis vindas do cosmos. (ONFRAY, 2016, p. 165).

O que de fato merece uma maior atenção no argumento de Onfray é o fato de que ecologia biodinâmica ${ }^{6}$ na relação com a teosofia, ele acredita que a antroposofia não superou sua filosofia mater, ou seja, a teosofia. Ele acredita que a antroposofia só produz efeitos naqueles que realmente acreditam nela, assim como toda a forma de ocultismo. Em certa medida, essa é uma crítica importante, porém, que não descarta o legado e a grandeza da obra de Steiner, logo, para o objetivo da presente pesquisa, iremos agora abordar o valor da concepção antroposófica para a

\footnotetext{
${ }^{5}$ Por meio de uma citação de Lamy, pensamos que justamente essa aproximação entre Steiner e Bachelard pode dar conta justamente desses dois aspectos da educação, a ligação com a terra e a técnica, que apesar de aparentemente opostos, são possivelmente complementares "Se nos referirmos à história das ideias, percebemos que é por referência a um modelo analógico, figurativo e figurativo, que primeiro tentamos pensar sobre a educação. Dois paradigmas podem ser invocados aqui: o primeiro é pensar a educação através da metáfora da agricultura, que é nutrir a alma e submetê-la a exercícios para garantir seu crescimento, no âmbito de uma imagem e uma semântica de crescimento, desenvolvimento, empurrão e até elevação. Educar consiste em dar a mistura certa de alimentos e exercícios, permitindo que o indivíduo desenvolva suas faculdades e se realize. Segundo sua natureza, unindo as condições ideais para o desenvolvimento de uma natureza que se orienta e enquadra, para fazer dela uma natureza humanizada de que se controla e se enquadra no delicado desenvolvimento. $O$ segundo modelo da ação educativa, ao contrário, tecnicista e produtivista, encaixa-se no contexto geral de uma produção, com base em uma imagem industrial e não artesanal. É sobre a produção de graduados, considerados como números. A educação consiste em adquirir as habilidades necessárias para ter sucesso na vida - incluindo a vida profissional - por meio de técnicas de aprendizado e habituação aos ritmos de trabalho. Educar não passa mais pelo exercício espiritual e pela comida da alma, mas depende de técnicas de fabricação ou mesmo condicionamento." (LAMY, 2014, p. 438).

${ }^{6}$ Foi um conceito elaborado por Steiner em 1924 a partir de um curso dado a agricultores, no qual ele identifica que uma faixa de terra a ser cultivada deve ser entendida como um organismo que integra o solo aos reinos vegetal e animal, esse entendimento dinâmico da agricultura significa a transformação constante seguindo as leis e ritmos do ambiente. "Na encruzilhada das ideias cristãs e teosóficas, R. Steiner defende uma ciência da saúde que pode ser considerada sincrética, porque um grande número de temas alternativos está ativo lá. Ele compartilha a crença em uma lei natural universal que o corpo deve respeitar. Mas, além do corpo físico, considerado, da maneira de Paracelso, entidades mais corporais, resíduos de seu passado, o corpo etérico, o corpo astral, que em última análise se refere a um destino, karma, que determina as restrições trans-individual. O homem, no entanto, é dotado de uma autoconsciência adicional que perturba a ordem da natureza. Plantas e metais estão de acordo com observações astrológicas favoráveis. A doença resulta, portanto, da falta de harmonia entre os três níveis do indivíduo: o sistema cefálico que organiza a percepção e o pensamento; o sistema metabólico que governa as trocas e movimentos, governa a ação e a vontade; e o sistema rítmico que conecta em princípio os outros dois. Cabe a todos encontrar o equilíbrio [...] sobre o princípio do método homeopático, que é estendido através de técnicas de agricultura tradicional e biodinâmica e mesmo por métodos da pedagogia e práticas artísticas" (WUNENBURGER, 2008, p. 89).
} 
ROCHA, Gabriel Kafure da; SANTOS, Debora Maria dos. PINHO, Ronald Oliveira.

educação. Assim, veremos a seguir, como Steiner e Bachelard também lidam com essa relação entre o simbólico e a infância.

\title{
ANTROPOSOFIA DA INFÂNCIA EM STEINER
}

\begin{abstract}
Duas palavras mágicas caracterizam a maneira como a criança se relaciona com o mundo: imitação e exemplo. O filósofo grego Aristóteles denominou o homem como o animal mais propenso a imitar; essa verdade vale para a idade infantil, até os sete anos, mais do que para qualquer outra. $O$ que acontece no ambiente físico a criança imita, e essa imitação confere aos órgãos físicos suas formas definitivas. (STEINER, 1996, p. 7).
\end{abstract}

Steiner concebe que o estudo da infância deve ser regido desde antes da criança nascer, seu processo formativo, até o primeiro setênio. É importante entender que para Steiner a criança não é uma tábula rasa, já que sua formação desde os genes é um processo de desenvolvimento das inteligências, sentimentos, comportamentos herdados que constituirão sua personalidade.

Steiner acredita que quando a criança nasce está em um estado de consciência resumida ao que acontece ao seu redor. As crianças começam as interações com o meio repetindo o que os adultos fazem, um dos primeiros sentimentos a ser trabalhado é o da segurança, desde o bem estar familiar, até na escola onde entrará em contato com jardins, árvores, balanços. Steiner considera que nesses primeiros anos de vida a criança deve ter contato com brinquedos feitos à base de madeira e argila, por serem elementos vivos.

A partir do momento que a criança começa a andar, ela parte a amadurecer o comportamento do cérebro relacionando os membros inferiores com o espaço. A própria fala está ligada também ao andar, pelo reconhecimento do espaço ela vai aprendendo a distinguir a realidade, a relação entre os hemisférios esquerdo e direito vão se aprimorando, a fala será o exercício de coordenar o pensamento da criança com objetividade e conectividade entre ideias.

Na pedagogia Waldorf, experiência originada por um convite à Steiner para dirigir uma escola, vemos uma experiência inovadora onde basicamente a relação entre o lúdico e o conhecimento teriam uma relação de horizontalidade e não de uma verticalidade do conhecimento sobre o lúdico. Assim, o objetivo é que a criança entenda o seu papel no mundo sem imposição dos pais ou da sociedade. Logo, as matérias criativas, artesanais e os afazeres domésticos tem um valor fundamental na educação, aprender a fazer pão, brincar com jogos orgânicos, despertam a imaginação e a inventividade é o objetivo da construção educativa da criança. O amor pela natureza valoriza a capacidade da criança por meio de atividades como subir nas árvores e caminhar na mata. Práticas como o tricô e outras atividades manuais são fundamentais para o desenvolvimento da coordenação motora e dos dois hemisférios cerebrais. 
Contos de fadas e o encantamento do mundo são incentivados até mesmo num sentido teológico onde os mitos de todos os continentes e raças são ensinados para que as crianças entendam a formação dos paradigmas do pensamento que vai do mito ao logos e que assim, criem seus próprios mitos pessoais, subjetivos, singulares. Associação entre bonecas e bonecos com detalhes faciais que desvelam imperfeições, mostrando a capacidade terapêutica desses "erros". E por fim, a aprendizagem de outras línguas, no caso principalmente a alemã, por meio de jogos e performances.

Veremos a seguir como Bachelard compreende a infância e como é possível uma relação com Steiner, a partir de uma mesma base no idealismo romântico alemão, no caso de Steiner, Goethe é uma influência indiscutível. Bachelard irá também se valer de outros poetas como Novalis, Rilke e mesmo do subjetivismo de Schelling e Fichte.

\section{DEVANEIOS DA INFÂNCIA EM BACHELARD}

" Não é a Escola que deve ser feita à imagem da Vida, mas a Vida que deve ser feita à imagem da Escola. " (BACHELARD, 1993, p. 12) Cientista, filósofo e poeta, Bachelard nos apresenta um universo onde o infantil não é tido como ingenuidade, mas como local (in locus) onde o hábito de poetizar se concretiza. Apresento também a compreensão de um poeta onde a infância o impulsionou, no berço de sua solidão a miniaturizar os objetos, isto é, a compreensão do mínimo. Por isso mesmo, a amplificação do olhar é necessária para um ser infantil. Um ser que vivencia sua casa e seus familiares.

O tempo da criança é um tempo veloz, e há idosos que são como crianças. Por isso tantos projetos, tanta vontade de entender o sonho. Mesmo a criança ou ainda o ancião, ambos estão imersos na vida. Embora Bachelard sempre se refira a cosmicidade do ser, este não se resume a estados de consciência, pois estados neste caso são inferiores aos planos das imagens.

Para Bachelard, há dois tipos de segmentos da imaginação: a formal e a material. A forma da imagem é bem parecida com a proposta idealista, embora não seja propriamente advinda da ideia, a contemplação é a base da proposta. Enquanto que a matéria se sobrepõe ao campo das formas, aí, a transformação e a deformação é que dão o caráter da criatividade ativa.

Qual é a educação da imaginação? A imaginação torna-se criativa apenas sob a condição de que não permaneça sob a dependência exclusiva das forças obscuras e anárquicas do 'Eu'. Sonhar, elaborar fiç̧ões, criar uma obra, não são as únicas forças impulsivas e involuntárias. É por isso que G. Bachelard faz questão de distinguir a imaginação espontânea, um espelho de fantasia de uma noite inconsciente e o devaneio engendrado pelo Cogito do sonhador. A imaginação noturna introduz uma divisão no ser e deixa na 
sombra um fluxo de imagens desintegradas. Ao contrário, o ego sonhador, quando consciente, é enérgico, extrovertido, capaz de captar no mundo as matérias e formas e transformá-las por uma força, criando novas imagens. (WUNENBURGER, 2014, p. 210).

Aqui, jaz uma problemática que é da ordem do símbolo, onde a imagem enquanto criação da imaginação material é anterior ao símbolo? Se compreendermos o imediato assim como explica Bachelard a imagem é imediata, o símbolo diz mais do que não diz ou não diz mais do que diz? No não-dito encontro a possibilidade do infinito. No dito encontro o caos, logo o silêncio só me permite simbolizar quando reconheço que entre o dito e o não-dito existem interferências mais exatas no sentido de que a fratura é que mostra o defeito de um não-pensar, logo o símbolo é posterior à imagem.

Como bem, o ânima é luz, e por assim dizer a alma é uma espécie de negação do ser: aqui é uma crítica brincalhona e propositalmente superficial ao romantismo alemão, das formas em Schelling e da fenomenologia em Hegel. A linguagem, portanto, da anima, é a que troca tudo e depois a organiza num sistema fechado, rígido olhar e do ser. Já o momento de se fazer ciência: $O$ animus, serve para compreender a possível ambiguidade em Bachelard, se for vista apenas de maneira lógico-formal. É necessário partir para o seu teor de ambivalência onde co-habitam valências que rejeitam em última instância: dualidade, dubiedade e vagueza. A ambivalência concebe sentimentos opostos, contraditórios, mais que comportam também os "dois" lados conflitantes e necessários. Ou seja, em Bachelard há o lado noturno e diurno do Ser, mas que se ampliam em pluralismos coerentes no sentido do perfeccionismo retificador. A sua revolução não é marxista, a sua psicanálise não é freudiana nem junguiana, embora deste se aproxime muito mais no que tange aos arquétipos (animus/ânima); fêmea-macho, essa dualidade se desdobra numa unificação na matéria, isto é, as potências contidas no interior da mente humana convergem para um estado ascensional que atinge o concreto como fruto da criatividade.

\begin{abstract}
Assim, testemunhamos a gênese de uma regulação psicológica, da qual G. Bachelard enfatizará as virtudes de formar um caráter duro. Assim, o erista da imaginação participa intimamente da Bildung, na formação de si mesmo, na educação, na cultura. Longe de nos aprisionar num entretenimento insignificante e fútil, a imaginação material contribui para o desenvolvimento do sujeito, para a força de seu caráter. Pois a educação bachelardiana lida com instâncias celestiais, a da razão, que contribui para a instrução científica, e a da imaginação, que ajuda a fortalecer a vontade. (WUNENBURGER, 2014, p. 96).
\end{abstract}

Ao percebermos que a infância conhece a infelicidade pelos homens. Na solidão, as crianças podem aprender a acalmar seus sofrimentos, como Bachelard costuma caracterizar o canto, como aquele espaço em que a criança se recolhe para re-encontrar o seu ser (não necessariamente por meio de um castigo 'pedagógico' onde a professora manda a criança para 
seu canto). A criança conhece a ventura de sonhar, como o grande refúgio para as imposições do mundo, como aquilo que nenhum adulto pode lhe dominar e que será mais tarde a ventura dos poetas. Como não sentir que há comunicação entre a nossa solidão onírica e as solidões da infância? Por esse questionamento, não é à toa que, num devaneio tranquilo, fruto de uma educação, seguiremos a inclinação que nos restitui às nossas solidões de infância na construção de suas verdades.

Mas esse interesse e esse respeito pela verdade, essa submissão ao objetivo pode ser alcançada de várias maneiras. As tarefas científicas a este respeito são eminentemente educativas. (BACHELARD, 1993, p. 11).

Portanto, a tese que queremos defender visam todos a fazer o reconhecimento da permanência, na alma humana, de um núcleo de infância. A infância por ser um devir, não pode ser imóvel, ela é sempre viva, fora da história, oculta para os outros, disfarçada em história quando a contamos, mas que só tem um ser real nos seus instantes de iluminação - ou seja, nos instantes de sua existência poética.

Uma infância potencial habita em nós. Quando vamos reencontrá-la nos nossos devaneios, no nosso bom humor infantil, nós revivemos as possibilidades de tornar a realidade menos dura. Sonhamos tudo o que ela poderia ter sido, sonhamos no limite da história e da lenda e com isso podemos reencantar o mundo desencantado pela repetição e automação da própria técnica dogmaticamente entendida. Pois a verdadeira técnica, de acordo com Bachelard, é a fenomenotécnica, ou seja, a técnica de criar e fabricar fenômenos.

Nesse sentido, a memória é também entendida como um fenômeno para atingir as lembranças de nossas solidões, idealizamos os mundos em que fomos quando uma criança solitária. Ao perceber a causa da idealização das recordações da infância, podemos estabelecer uma comunicação entre a poética da infância como aquilo que permanece em nós. Essa infância, aliás, permanece como uma simpatia de abertura para a vida, permite-nos compreender e amar as crianças, permite-nos reconhecer, como aquilo que fomos e aprender novamente a resgatar isso em nós.

Passaremos agora a trabalhar por fim a juventude como consequência da infância, ou terceiro setênio é a possibilidade de transição ao dizer não para o mundo, tendo a verdadeira capacidade de julgamento que os levará a ser indivíduos éticos.

\section{Praxeologia}

Vamos agora traçar as três ideias norteadoras, a fim de enquadrar precisamente os desenvolvimentos gerais desta última parte: 1) a transformação do indivíduo, orientada para o advento de um estado superior de self (finalidade); 2) prática pessoal, através de 
exercícios concretos, como vetor concreto de autotransformação (método); 3) a pluralidade de formas de atingir um estado melhorado de si mesmo, de acordo com contextos praxeológicos distintos (modalidades). Ressaltamos que este último aspecto, segundo nos, é a originalidade de Bachelard na orientação da filosofia moral, não apenas na perspectiva do perfeccionismo (ou mímica), mas também no contexto da reflexão ética contemporânea. (LAMY, 2014, p. 400)

Pela praxeologia moral, após entendermos como é a vida na infância em Bachelard e Steiner, é possível entender agora como ela se relaciona como uma possibilidade de modelo educacional. Podemos então agora considerar que Bachelard entende o perfeccionismo como fenômeno ético e pedagógico que norteia um pluralismo metodológico para ciência ou para a educação, encontramos então nessa metodologia um princípio de para nossa prática acadêmica. Assim, por meio da atividade científica, vemos que ao estudar, o homem é uma promoção do ser e nessa possibilidade ele pode conjugar suas conversões científicas e poéticas.

O exercício prático do perfeccionismo é basicamente a luta contra os obstáculos epistemológicos e poético-oníricos. Esse é um trabalho de modificação da maneira de conceber o próprio processo subjetivo de formação do conhecimento. Em A formação do espírito científico, por exemplo, Bachelard sugere que isso implica numa análise, ou melhor, psicanálise do conhecimento, no qual é necessário depurar esses obstáculos para superá-los. No caso da presente investigação, pretendemos depurar a possibilidade de aproximação entre Steiner e Bachelard, e, assim, superar a crítica de Onfray sobre uma inferioridade de um em relação ao outro. Nesse caso, entendemos que o processo de dessubjetivação implica numa nova resubjetividade, ou seja, numa transformação do efeito performativo do indivíduo. Isso nos parece justamente a "dimensão de espiritualidade moral perfeccionista" (LAMY, 2014, p. 418).

Paralelamente a essa nossa tese, encontramos na tese de doutorado de Steiner, A filosofia da liberdade, também um direcionamento para essa contemplação e reflexão da perfeição por meio da observação da natureza. Notem:

\footnotetext{
Observamos num organismo crescimento e desenvolvimento até um certo grau de perfeição; podemos então analisar as condições que determinam esses fatos. Nunca é, pois, suficiente o que a natureza apresenta aos sentidos. Precisamos avançar e procurar o excedente, que chamamos de explicação dos fatos. (STEINER, 1988, p. 8).
}

Contudo, para Steiner, a perfeição não é apreendida somente pela observação, mas também pela intuição. De maneira correlata, Bachelard entende que o vício da ocularidade é um obstáculo ao conhecimento, contudo, nas várias fases de seu pensamento, ele faz críticas e depois descontinuamente chega a fazer uma apologia à intuição, como em seu livro $A$ intuição do instante, em que a tese da descontinuidade se estabelece como função do tempo e da vida. Sua 
ROCHA, Gabriel Kafure da; SANTOS, Debora Maria dos. PINHO, Ronald Oliveira.

crítica se dá ao fato de que intuição individuais atrapalham o processo científico que deve ser essencialmente racional e universalizante. Contudo, 'intuições' também podem se transformar em processos da racionalidade científica, como a ideia do átomo (um processo dedutivo da decomposição da realidade intuitivo), ou talvez ainda simplesmente as intuições possam se tornar devaneios.

Numa das últimas frases da tese de Steiner,

$O$ individualismo ético não precisa temer uma ciência natural coerente. A observação leva à liberdade como forma mais perfeita da acão. A liberdade tem que ser atribuída ao agir humano desde que ele realize puras intuições ideais, pois estas não são o resultado de uma influência externa, mas algo baseado em si mesmo. Sendo uma ação a imagem de uma intuição ideal, ela é sentida como livre. Eis o que caracteriza a ação livre. (STEINER, 1998, p. 59).

A contribuição da reflexão bachelardiana se coloca assim como uma possibilidade de explicação psicológica das ações em direção ao conhecimento. Assim o gosto pelo trabalho ${ }^{7}, 0$ esforço criador levam ao projeto racional da realização concreta pela transformação de si no sentido da liberdade. É aí que a infância representa um arquétipo fundamental, onde o maravilhamento pelo mundo é uma espontaneidade que revela um modo de ser no mundo. E esse é o modelo da educação perseguido por ambos os pensadores em questão, ou seja, um modelo de educação aberto a novidade e nas melhores experiências que podem modificar a maneira de pensar e a cognição dos sujeitos.

\section{Conclusão: moral e juventude}

Os belos sentimentos gerados por semelhante experiência permanecerão entre as reminiscências mais duradouras da vida. Feliz é o adolescente que pode elevar seu olhar para o mestre e educador como autoridades naturais, e isso não apenas em alguns momentos excepcionais, mas durante toda a juventude! Além dessas autoridades vivas, verdadeiras encarnações da força moral e intelectual, deve haver as autoridades espiritualmente aceitas. (STEINER, 1996, p. 9).

A síntese entre o pensamento de Bachelard e Steiner por meio da consequência (des)contínua da infância que é a juventude, temática trabalhada na chamada conferência de Cracóvia, o texto $O$ valor moral da cultura científica, que já viemos trabalhando nas seções anteriores, tem talvez o legado enquanto texto que representa uma aproximação entre a ideia de

\footnotetext{
${ }^{7}$ Por ser uma filosofia relacional, ou seja, onde sujeito e objeto se constroem mutuamente, no caso da educação o mestre-aprendiz também se constroem mutuamente, sendo ambos (professor e aluno), mestres-aprendizes. Assim, como bem pontua Fabre: "A filosofia de Bachelard é um pensamento de trabalho: trabalhar conceitos, trabalhar em imagens, trabalhar em assuntos. No trabalho, é a estrutura do objeto que comanda: só pode ser transformado pela obediência a ele! Inversamente, [Para Bachelard] nenhuma transformação de objetos sem transformação de si mesmo" (FABRE, 1995, p. 4 - grifos nossos).
} 
ROCHA, Gabriel Kafure da; SANTOS, Debora Maria dos. PINHO, Ronald Oliveira.

moral, educação e ciência em Bachelard. Ao começar pela temática da atividade social como o problema social da educação moral, Bachelard entende que a universalização da subjetividade requer atenção no sentido moral.

É por isso que G. Bachelard recomendou na educação a realização de dois universos simbólicos opostos, seguindo dois caminhos específicos de formação e maturação, que exigem uma ruptura simétrica com a vida cotidiana ou a cultura dominante. $O$ primeiro será através da disciplina escolar do ensino científico que terá que contrariar os afetos do 'Eu' por uma socialização da razão, o segundo, ao contrário, terá que se dar os meios de uma reapropriação da imaginação através dos ritmos corporais, devaneios em contato com matérias e movimentos, alegrias do verbo poético, imaginação poética, por outro lado, o único indivíduo que nunca acessa mais intensamente as energias criativas das imagens do que na solidão. A recompensa daqueles que, longe das injunções da razão pragmática ou normativa, se dedicam ao lazer, à caminhada, à leitura. (WUNENBURGER, 2014, p. 187).

Seu interesse é entender em que medida o direito moral se diferencia da atividade científica dado que tais atividades são respectivamente prescritivas no modo imperativo e indicativo. Bachelard entende que a realidade da ciência é tão abstrata quanto a moralidade.

Percebemos então que a matéria obedece à mente. Como, então, a mente não obedeceria ao espírito, à consciência moral à razão? Que súbita timidez nos leva diante da informação racional da consciência moral? Na minha opinião, nada se opõe a uma educação moral moralmente racional, a uma conduta moral inteiramente baseada na razão pura. A criança deve ser confrontada com o caráter absoluto e universal das regras morais que são objetivas como a verdade. É mais cedo mostrar o caráter necessário da lei moral do que seu caráter geral. A criança também é muito apta a receber esta lição da necessidade e do absoluto. Pode-se até dizer que a adolescência é a idade do absoluto, a idade da máxima eficiência da verdade. (BACHELARD, 1993, p. 9).

Bachelard entende que a ciência é educativa e que na adolescência tal tendência encontra o ápice de sua potencialidade, assim, se o seu ensino deve iniciar-se justamente na infância, visto que se tal atividade for voltada para fins morais e espirituais, então é na adolescência que o ser humano estará mais aberto à capacidade de reforma do pensamento.

Me parece que a atualidade da lição de Bachelard é exemplificar para nós que a escola está dividida, em geral, em duas tentações radicais e ambas nocivas à criança e ao adolescente de hoje: ou se 'força' a inteligência e a memória da criança para que se converta o homem às 'tecnoestruturas' da sociedade pós-industrial, ou se espera que o dinamismo espontâneo da afetividade e da imaginação transforme o indivíduo, evitando recorrer a saberes inúteis. [...] Bachelard não traz, certamente, nenhuma solução, nenhuma receita, mas sim exigências 'de uma vanguarda' que considera útil e urgente explorar, ainda que somente para justificar, as intenções pedagógicas inovadores, arriscados, e não meras aventuras. (JEAN, 1989, p. 23).

Assim, não há solução além de ir em direção as extremidades e as antípodas das experiências pedagógicas, do mais rural ao mais técnico, não há solução além da complementariedade. E nisso, o treinamento moral é indissociado do treinamento intelectual da aceitação desse paradoxo, e é justamente no momento da transmissão do conhecimento que é 
ROCHA, Gabriel Kafure da; SANTOS, Debora Maria dos. PINHO, Ronald Oliveira.

possível apreender o valor ético da realidade. E nisso, Bachelard constata que a sociedade tende a limitar a atividade intelectual da escola, muitas vezes se interessando somente pela criação moral, quando na verdade, a escola deve ser o modelo moral da sociedade. Ora, isso diz muita coisa, que devemos eternamente retornar à escola e seus ideais de abertura racional como a vida moral da adolescência, onde as mentes se retificam, constituem e se universalizam na ideia de uma juventude criadora de valores.

\begin{abstract}
O jovem precisa aprender, para o cultivo de sua memória, coisas que só mais tarde compreenderá intelectualmente. Aprende-se mais facilmente a conceituar o que, nessa idade, foi assimilado apenas pela memória da mesma forma como se aprende melhor as regras de uma língua que já se sabe falar. A alegação de matéria decorada e incompreendida não passa de preconceito materialista. Basta, por sinal, que o jovem aprenda as leis elementares da multiplicação mediante alguns exemplos em que não é preciso usar máquina calculadora, e sim de preferência os dedos; depois ele deve decorar ordenadamente as tabuadas. Se procedermos assim, estaremos agindo de acordo com a natureza do ser humano em crescimento. Estaremos pecando contra essa natureza se exigirmos demais do intelecto numa época em que o que se deve cultivar é a memória. 0 intelecto é uma força anímica que nasce apenas com a puberdade, e sobre a qual, por isso, não seria conveniente atuar antes dessa idade. Antes da puberdade, o jovem deveria assimilar pela memória o acervo mental da humanidade. (STEINER, 1996, p. 11).
\end{abstract}

Por fim, entendemos que essa experiência de aproximação pode ter ainda diversas bifurcações que aprofundem principalmente a relação entre a materialidade da educação numa perspectiva inovadora como a Waldorf e uma idealidade dogmática da educação massiva que não consegue dar conta da relação entre o conhecimento necessário a ser transmitido e a aplicação no mundo para a uma existência autônoma.

Defendemos uma leitura perfeccionista da ética bachelardiana, cuja linha principal consiste em articular a possibilidade do bem viver, como promoção da existência, mesmo como superexistência, com a prática do auto-exercício permitindo uma transformação concreta da individual, na perspectiva de um pluralismo coerente de modos de existência e, conseqüentemente, de uma pluralidade de formas da boa vida. (LAMY, 2014, p. 403).

Assim, esperamos ter aberto um novo caminho para entendimento de como o pluralismo coerente é a capacidade de encontrar sínteses sobre as semelhanças e diferenças entre diversos espíritos do tempo, mas que se assemelham em certos aspectos mesmo sem ter se ligado diretamente. Notamos que ambas as concepções de mundo procuram a abertura entre os mundos antigos e contemporâneos por meio do aperfeiçoamento constante do ser humano para viver melhor e mais integrado com o cosmos. É necessário entender que perfeccionismo seja uma espécie de eugenia, muito pelo contrário, é justamente a aceitação das condições humanas adversas e a valorização da tentativa de superação, sendo assim, ao invés de uma meritocracia, 
uma pedagogia da singularidade, que valoriza a pluralidade e a multiplicidade enquanto potencializadoras da vida e do ser.

Com medo e ansiedade, então felicidade e contentamento. Longe da tristeza acadêmica, Bachelard retrata toda a dimensão subversiva de um pensamento em primeira pessoa, radicalmente subjetivo, revertendo o sonho como um método quase mais seguro de alcançar a certeza de que qualquer artifício racional. (ONFRAY, 1998, p. 13).

Por fim, percebemos que Onfray, apesar de perceber a importância da imaginação para Bachelard, ainda assim não compreende o poder da imaginação como realizadora também de técnicas pedagógicas, homeopáticas, enfim, antroposóficas, o que é muito diferente da interpretação de Wunenburger (2008), que é também um importante comentador de Bachelard e dos estudos do imaginário. Ainda assim, Onfray compreende que há na filosofia da imaginação um aspecto subversivo, quiçá libertário, que pode sim estimular a criticidade nesse processo que vai da infância à juventude.

\section{Referências}

ARIÈS, Philip. (1960) História social da criança e da família. Rio de Janeiro: Guanabara, 1981.

BACHELARD, Gaston. (1934) Valeur morale de la cultura scientifique. 6e Congrès International d'éducation morale. Cracovia. In: GIL, Didier. Bachelard et la culture scientifique. Paris: PUF, 1993. pp. 7-12.

Fontes, 2001.

(1943) O ar e os sonhos: ensaio sobre a imaginação do movimento. São Paulo: Martins . (1960) A poética do devaneio. Tradução Antônio de Pádua Danesi. São Paulo : Martins Fontes, 2009.

BUCKINGHAM, David. (2000) Crescer na Era das Mídias Eletrônicas. São Paulo: Edições Loyola, 2007.

DURAND, Gilbert. (1964) A imaginação simbólica. Lisboa, Portugal: Ed. 70, 1993.

FABRE, Michel. Bachelard éducateur. Paris: PUF, 1995.

JEAN, Georges. (1983) Bachelard, la infância y la pedagogia. Trad. Juan José Utrilla. México: Fondo de cultura econômica, 1989.

LAMY, Julien. Le pluralisme cohérent de la philosophie de Gaston Bachelard. Tese de Doutorado em Filosofia. Université Lyon III, 2014.

ONFRAY, Michel. Hommage à Bachelard. Paris: Editions du Regard: 1998. 
ROCHA, Gabriel Kafure da; SANTOS, Debora Maria dos. PINHO, Ronald Oliveira.

. Cosmos: uma ontologia materialista. São Paulo: Martins Fontes, 2016.

ROMANELLI, Rosely. (2015) A cosmovisão antroposófica: educação e individualismo ético. Educar em Revista, Curitiba, n. 56, p. 49-66, abr./jun.

SARMENTO, Manuel Jacinto. As culturas da infância nas encruzilhadas da $2^{a}$ modernidade. Braga: Instituto de Estudos da Criança, Universidade do Minho, 2003.

STEINER, Rudolf. (1893) A Filosofia da Liberdade. 2. ed. São Paulo: Ed. Antroposófica, 1988. . (1907) A Educação da Criança Segundo a Ciência Espiritual. Trad. R. Lanz. São Paulo: Ed. Antroposófica, 3a ed. 1996.

WUNENBURGER, Jean-Jacques. Imaginaires et Rationalité des Médecines Alternatives. Paris: Les Belles Lettres, 2008.

. Gaston Bachelard, poétique des images. Paris: Editions Mimesis, 2014. 